\title{
A pH-responsive liquid crystal hydrogel actuator with calcium-induced reprogrammable shape fixing
}

Simon J. A. Houben, Sean J. D. Lugger, Roel J. H. van Raak, Albert P. H. J. Schenning*

Laboratory of Stimuli-responsive Functional Materials and Devices, Department of Chemical

Engineering and Chemistry, Eindhoven University of Technology, P.O. Box 513, 5600 MB, The

Netherlands

Corresponding Author

*a.p.h.j.schenning@tue.nl 

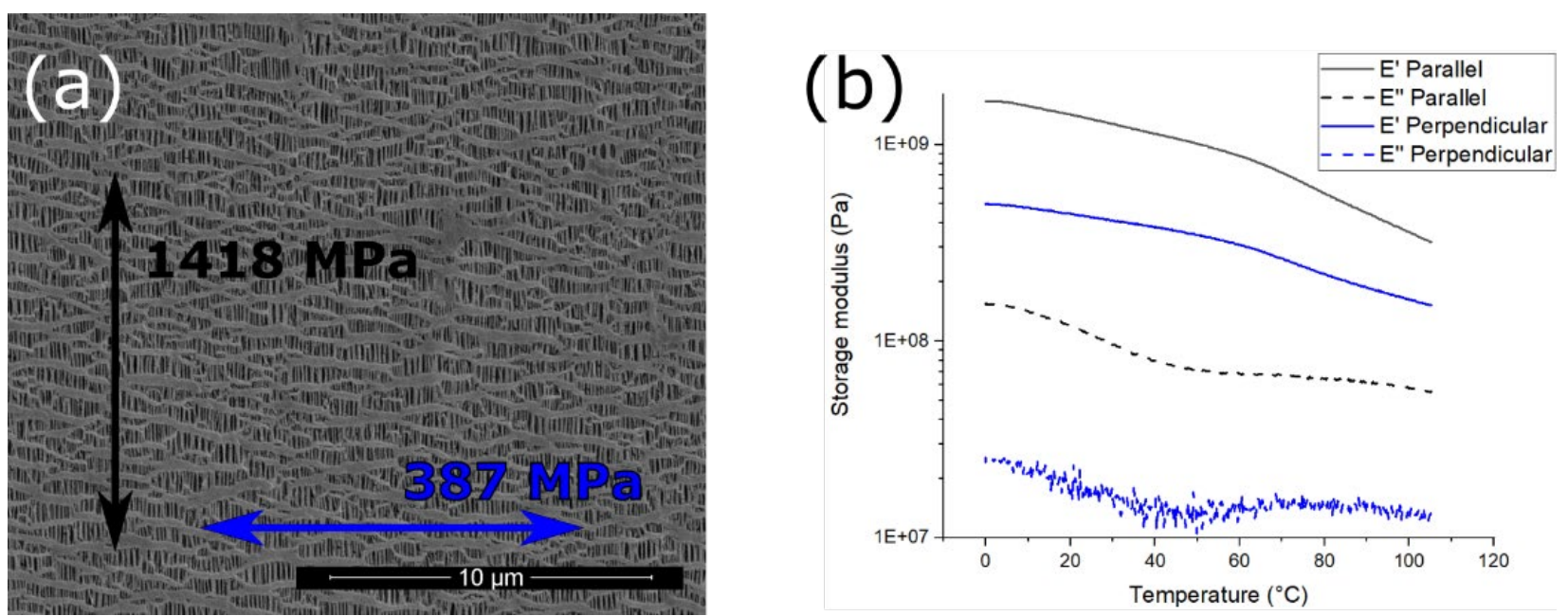

Figure S1: (a) SEM image of the PP scaffold showing the small fibrils (vertical) and larger girders (horizontal) with $E^{\prime}$ of both directions at $20^{\circ} \mathrm{C}$. (b) DMA graph of the storage $\left(E^{\prime}\right)$ and loss (E', moduli of the scaffold parallel (black) and perpendicular (blue) to the fibril direction

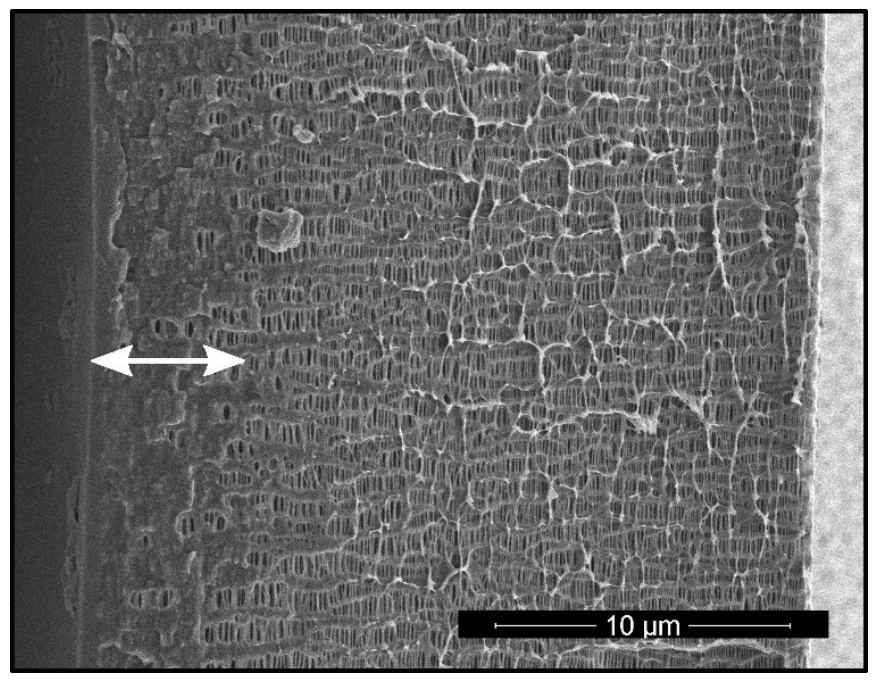

Figure S2: SEM images of the pristine $40 \% \mathrm{Cl}$ LCN-PP actuator. A dense $\sim 5 \mu \mathrm{m}$ thick LCN layer on the left side of the scaffold is visible as indicated by the white arrow. 
S3: FT-IR

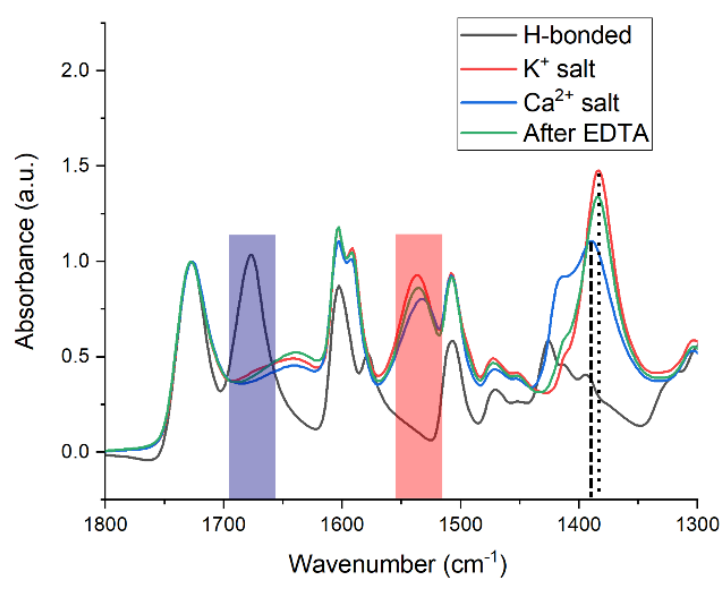

Figure S3: FT-IR spectra of the $10 \% \mathrm{Cl}$ LCN-PP actuator in the H-bonded $\left(1680 \mathrm{~cm}^{-1}\right.$, marked in blue) and polymer salt $\left(1540 \mathrm{~cm}^{-1}\right.$, marked in red.) states. The $\mathrm{K}^{+}$and $\mathrm{Ca}^{2+}$ salts have a distinct absorption peak at $1384 \mathrm{~cm}^{-1}$ (dotted line) and $1390 \mathrm{~cm}^{-1}$ (dashed line) respectively. After removal of the $\mathrm{Ca}^{2+}$ ions with EDTA the $\mathrm{K}^{+}$salt is reformed.

Video S1: Actuation of the $10 \% \mathrm{Cl}$ LCN-PP actuator in the hydrogen state submerged in a 0.1 $\mathrm{M} \mathrm{KOH}$ solution. The composite film was cut perpendicular to the fibril direction (Figure 2d). 